\title{
Determination of Zinc and Cadmium with Characterized Electrodes of Carbon and Polyurethane Modified by a Bismuth Film
}

\author{
Jossy Karla Brasil Bernardelli, ${ }^{\mathrm{a}, \mathrm{*}}$, Flávio Rubens Lapolli ${ }^{\mathrm{b}}$, \\ Carlos Marcus Gomes da Silva Cruza, João Batista Floriano ${ }^{\mathrm{a}}$ \\ ${ }^{a}$ Academics Department of Chemistry \& Biology, \\ Federal University of Technology of Paraná - UTFPR, \\ Av. Sete de Setembro 3165, CEP 80230-901, Curitiba, PR, Brazil \\ ${ }^{\mathrm{b}}$ Graduated Program in Environmental Engineering, \\ Federal University of Santa Catarina - UFSC, \\ Campus Universitário, Trindade, CP 476, CEP 88040-970, \\ Florianópolis, SC, Brazil
}

Received: March 16, 2011; Revised: July 7, 2011

\begin{abstract}
This study aims to use electrodes modified with bismuth films for the determination of zinc and cadmium. The film was electrodeposited ex situ on a composite carbon electrode with polyurethane and $2 \%$ metallic bismuth $(2 \mathrm{BiE})$ and on a carbon bar electrode (CBE). The electrodes were characterized by scanning electron microscopy and energy dispersive spectroscopy. Through differential pulse anodic stripping voltammetry, the electrodes $2 \mathrm{BiE}$ and CBE containing bismuth films showed a limit of detection (LOD) of $5.56 \times 10^{-5}$ and $3.07 \times 10^{-5}$ g.L. $\mathrm{L}^{-1}$ for cadmium and $1.24 \times 10^{-4}$ and $1.53 \times 10^{-4}$ g.L. $\mathrm{L}^{-1}$ for zinc, respectively. The presence of a bismuth film increased the sensitivity of both electrodes.
\end{abstract}

Keywords: voltammetry, modified electrode, metals, bismuth film

\section{Introduction}

Despite the high toxicity of mercury, this element has been widely used as the working electrode in the form of a film or hanging drop, due to its excellent analytical properties, which provide optimum performance for electrochemical analysis. However, its toxic properties restricts the continued use of this element as an electrode material, and intensive research has been attempted to introduce electrodes with less toxicity and that are more environmentally friendly than mercury ${ }^{1-3}$.

The bismuth film electrode (BiFE) has been introduced as an alternative to the mercury electrode for electrochemical stripping analysis of trace heavy metals. The existing relevant data suggest that the performance of the $\mathrm{BiFE}$ is comparable to that of the mercury film electrode in anodic stripping voltammetry (ASV) and adsorptive stripping voltammetry $(\mathrm{AdSV})^{4}$.

Bismuth can be incorporated into the electrode in different ways: a) Electrodeposition ex situ involves the formation of the Bismuth film prior to the analytical sequence, separate from the Bi (III) solution ${ }^{5}$. The conditions for electrodeposition of the film are particularly variable. An acidic solution is always recommended because bismuth is easily hydrolyzed at high $\mathrm{pH}^{6}$; b) Electrodeposition in situ is based on spiking the sample with Bi (III) ions, and the formation of the bismuth film occurs simultaneously with the analyte accumulation step $^{5}$. In this case, the electrodeposition conditions are determined by analysis; c) Incorporation of the modifier directly into the body of the electrode during the preparation of carbon paste electrodes. This electrode is easy to manufacture and simplifies the experimental procedure for promoting a film without using salts of bismuth íon ${ }^{6}$.

Nevertheless, it has to be considered that in those studies where the presence of $\mathrm{Bi}(\mathrm{III})$ ions can seriously disturb the medium (e.g., heavy metal speciation), the ex situ methodology has as a clear advantage?

The deposition of bismuth films can be preceded on different substrates. BiFEs have been deposited on carbon substrates. These include screen-printed carbon $^{7}$; carbon paste with silicone oil ${ }^{8}$; carbon fiber microelectrodes ${ }^{9}$; carbon fiber electrode ${ }^{10}$; glass carbon covered with Nafion ${ }^{11}$; a graphite electrode (pencil-lead) and a nitrogen-doped diamond-like carbon (NDLC) microelectrode ${ }^{12}$. Such films used for the determination of heavy metals, mainly cadmium, lead and zinc, show some advantages in comparison to mercury-based electrodes.

The carbon paste electrode represents a promising substrate for the electrochemical deposition of films. This electrode has several advantages, including easy modifiability and the capability to obtain a reproducible surface by simply polishing with paper $^{13}$. This electrode is composed of carbon powder and an insulator, also called agglutinant. The modification of carbon paste electrodes by a chemical compound (chemically modified electrode) has a great influence on the behavior of the electrodes ${ }^{14}$. The carbon-polyurethane composite electrode was used for the determination of hydroquinone ${ }^{15}$, cadmium $^{16}$, atenolol and paracetamol ${ }^{17}$, indole-3-acetic acid ${ }^{18}$ and other compounds.

In their work, Cesarino et al. ${ }^{19}$ studied the determination of the metals zinc, cadmium, lead, copper and mercury using a graphitecastor oil polyurethane composite electrode with a bismuth film electrodeposited in situ. The authors showed that it is possible to determine metals reoxidized at potentials both more negative and more positive than $\mathrm{Bi}$.

The aim of this study was to construct, apply, compare and characterize two electrodes, a composite carbon electrode with 
polyurethane and $2 \%$ metallic bismuth $(2 \mathrm{BiE})$ and a carbon bar electrode $(\mathrm{CBE})$ as well as these electrodes modified with bismuth films electrodeposited ex situ, (2BiFE) and (BiFCBE), respectively. The electrodes were applied for the determination of cadmium and zinc in acetate buffer $\mathrm{pH} 4.5$ by differential pulse anodic stripping voltammetry (DPASV).

\section{Experimental}

The three-electrode cell with $50 \mathrm{~mL}$ total capacity was used with a working electrode (electrode under study), a reference electrode (Ag/ $\mathrm{AgCl} / \mathrm{KCl}(\mathrm{Sat})$ ) and a counter electrode (platinum). Voltammetric experiments were performed using a potentiostat/galvanostat, model 273A EG\&G, coupled to a personal computer with software. Prior to the electrochemical measurements, the solutions were deoxygenated by purging with nitrogen for 10 minutes $^{20}$.

The composite electrode was inserted in a manual press with a load of $17 \times 10^{3} \mathrm{~kg} \cdot \mathrm{cm}^{-2}$ and extruded as $3.0 \mathrm{~mm}$ diameter rods ${ }^{17}$. For characterization, we used a scanning electron microscope with energy dispersive spectroscopy, model JEOL JSM - 6360LV, the samples were photographed at different magnifications using $15 \mathrm{kV}$.

Figure 1 shows how the chemically modified electrode was prepared. Figure 2 shows the steps of preparing the carbon paste. We used the following $3 \mathrm{~mm}$ electrodes: carbon bar (CBE), composite with $2 \%$ metallic bismuth embedded ( $2 \mathrm{BiE})$, bismuth film electrodeposited in $\mathrm{CBE}$ (BiFCBE) and bismuth film electrodeposited in $2 \mathrm{BiE}(2 \mathrm{BiFE})$.

The experimental parameters to DPASV were as follows: potential range of -1.4 to $-0.6 \mathrm{~V}$ for zinc and -1.3 to $-0.5 \mathrm{~V}$ for cadmium, deposition time 60 seconds, scan rate $(\mathrm{v}) 30.77 \mathrm{mV} / \mathrm{s}$, pulse height of $90 \times 10^{-3} \mathrm{~V}$ and a scan increment of $2.00 \mathrm{mV}$; concentrations of $1.00 \times 10^{-4}$ to $1.47 \times 10^{-3} \mathrm{~g} . \mathrm{L}^{-1}$ of cadmium and $3.33 \times 10^{-4}$ to $3.00 \times 10^{-3} \mathrm{~g} . \mathrm{L}^{-1}$ of zinc, and $0.1 \mathrm{~mol} . \mathrm{L}^{-1}$ acetate buffer solution $(\mathrm{pH}=4.5)$ as the supporting electrolyte.

The electrochemical deposition of bismuth on the different substrates was by potential pulses using the following parameters: pulse potential of -0.05 to $-0.15 \mathrm{~V}$, with pulse duration of 300 seconds, and a concentration of $0.02 \mathrm{~mol} . \mathrm{L}^{-1} \mathrm{Bi}$ in $1.0 \mathrm{~mol} . \mathrm{L}^{-1} \mathrm{HNO}_{3}$. After the electrochemical deposition, the $\mathrm{BiFCBE}$ and $2 \mathrm{BiFE}$ were rinsed with deionized water and immersed into the test solution.

\section{Results and Discussion}

\subsection{Characterization of bismuth film electrodes}

Figure 3 presents the SEM images taken through the electrodes with electrodeposited bismuth film ex situ. It is observed that the figures of films formed on different substrates have very similar sizes and characteristics and that the distribution of bismuth particles is more uniform on 2BiFE. Agglomeration of these particles occurred on BiFCBE.

Moreover, it is clear from Figure 3 that the light, dendritic areas, are rich in bismuth and that the dark area represents the surface of the substrate. The film does not coat the entire surface of the electrode in both of these cases. Therefore, the responses obtained in the analysis of cadmium and zinc show different results, as noted. This fact was expected, considering that approximately $30 \%$ of the electrode surface $2 \mathrm{BiE}$ is nonconductive.

Hutton et al. ${ }^{9}$ also observed the surface of the substrate clearly exposed between the crystals of bismuth, after ex situ electrochemical deposition of the bismuth film using a solution containing added $\mathrm{Bi}^{3+}$ ions.

According to Wang et al. ${ }^{2}$, the carbon substrate has a profound effect upon the nucleation and growth of the bismuth deposit and, hence, upon structural features.

The deposits obtained by Baldrianova et al. ${ }^{21}$ in a carbon paste electrode after electrodeposition in situ had started to thicken in a non-uniform manner, forming dendritic structures that were typical of uneven deposition, which was very similar to what was observed in this work.

Figure 4 shows the percentage of carbon, oxygen and bismuth present in the bismuth film electrodes analyzed by EDS. The general region is identified as relating to the field analysis conducted in a region of the sample, and the light and dark regions refer to the determination of the percentage of punctual elements. It can be seen that the percentage of bismuth is significantly higher in the light region of the image and lower in the dark region.

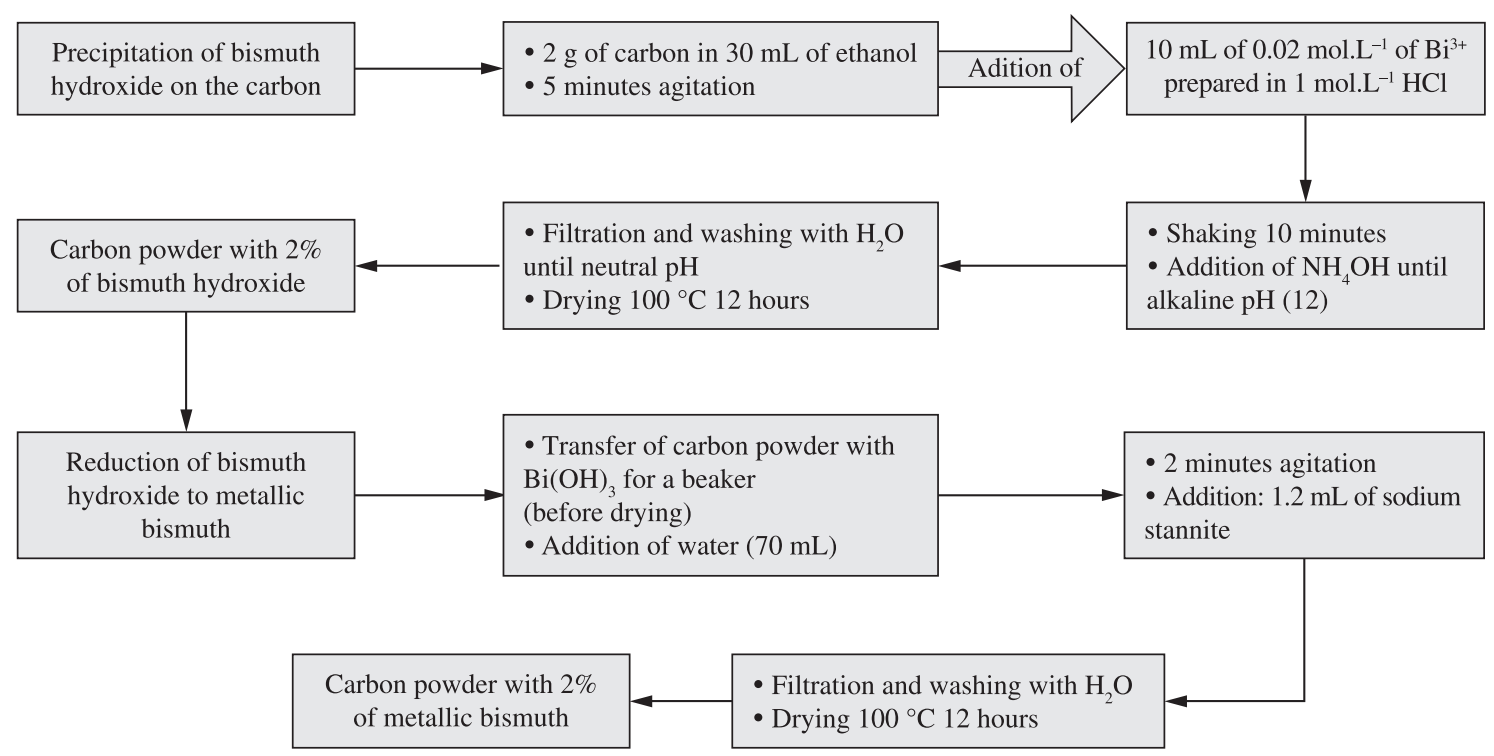

Figure 1. Schematic diagram of the processes of precipitation and reduction of bismuth on carbon particles. 


\subsection{Analytical performance of the electrodes in the determination of cadmium and zinc}

A series of voltammograms of differential pulse anodic stripping obtained with the electrode $2 \mathrm{BiE}$ for solutions of acetate buffer ( $\mathrm{pH} 4.5$ ) containing increasing concentrations of cadmium $\left(1.00 \times 10^{-4}\right.$ to $1.47 \times 10^{-3}$ g.L. $\left.{ }^{-1}\right)$ and increasing concentrations of zinc $\left(3.33 \times 10^{-4}\right.$ to $3 \times 10^{-3}$ g.L. $\left.\mathrm{L}^{-1}\right)$ is illustrated in Figure $5 \mathrm{a}$ and $\mathrm{b}$ respectively. It was observed that, in the determination of cadmium and of zinc, all the peaks are well resolved and increase linearly with metal concentration for both the electrodes without the bismuth film. Also, the peak currents were higher with the CBE.

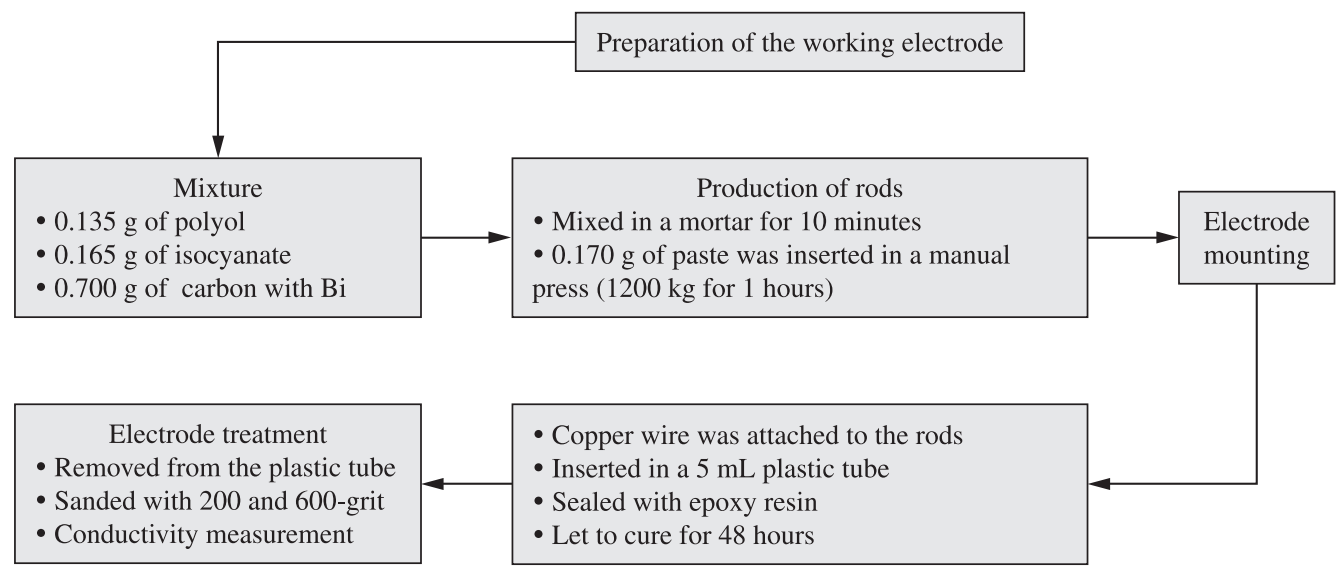

Figure 2. Schematic diagram of preparation of the electrode.

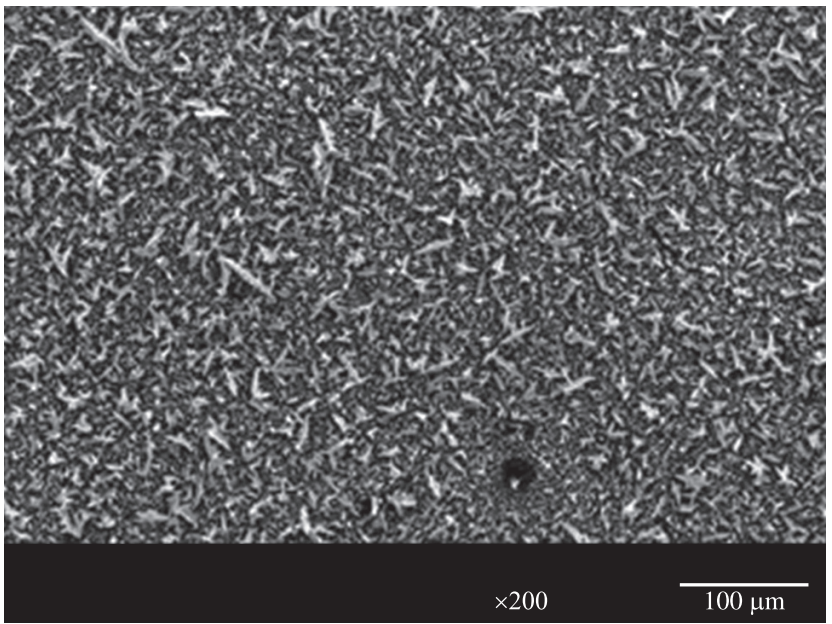

(a)

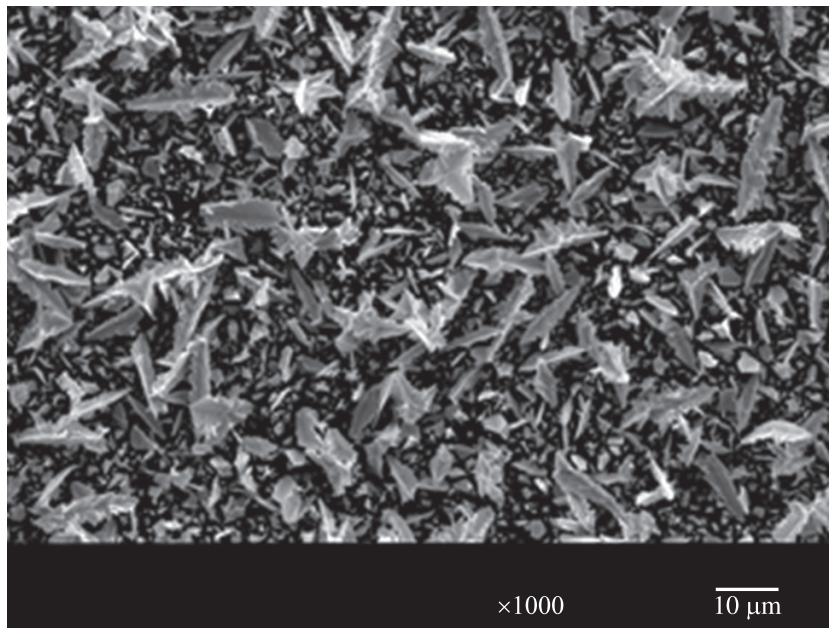

(c)

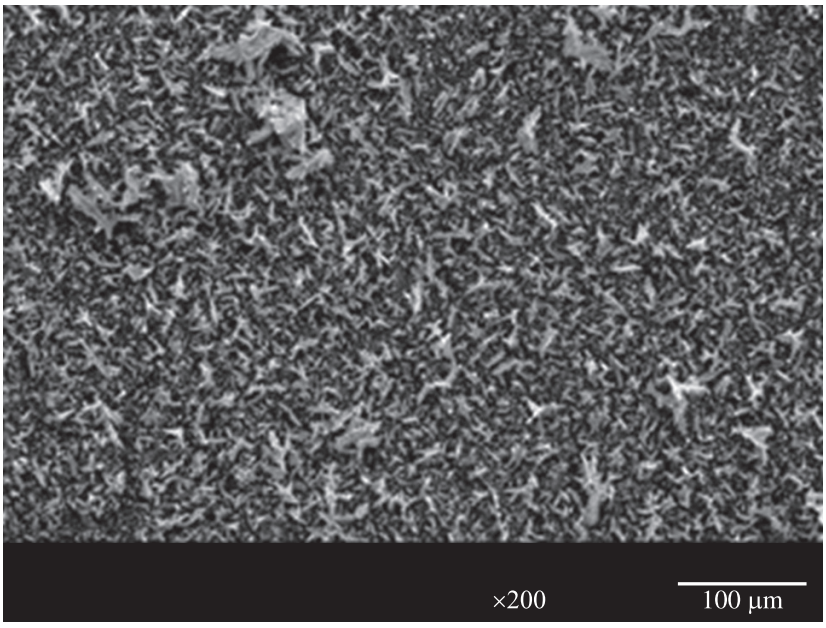

(b)

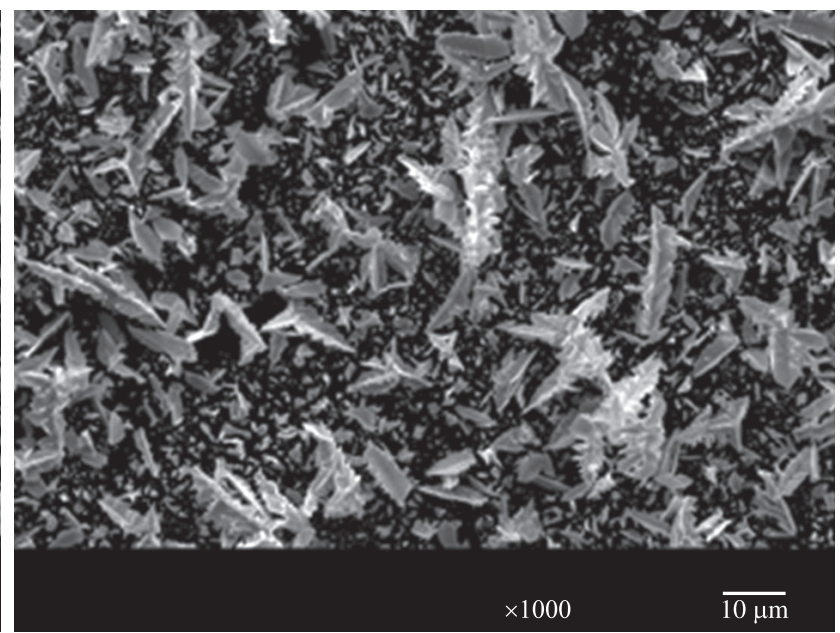

(d)

Figure 3. SEM image of the surface of bismuth film electrodes: $2 \mathrm{BiFE}(\mathrm{a}, \mathrm{c})$ and BiFCBE (b, d) at varying magnifications. 
For the cadmium determination, the voltammograms of differential pulse anodic stripping of the electrodes with a bismuth film (2BiFE and BiFCBE), in comparison to the same electrodes without the film, showed a widening of the peak for all concentrations. The electrodes with a bismuth film also showed a displacement of the peak potential towards a less negative potential, especially for the first three concentrations.

This fact can be explained by irregular electrodeposition of the film because the particles of bismuth are not evenly distributed and have different sizes. Additionally, they provided a large slope of the baseline due to the reduction of hydrogen ions. Despite these differences, the electrodes with films showed greater sensitivity in the determination of cadmium than the electrodes without films.

It was observed that the peaks of zinc are well defined for the electrodes $2 \mathrm{BiFE}$ and BiFCBE. However, there is reduction of hydrogen ions, which provides a greater slope of the baseline.

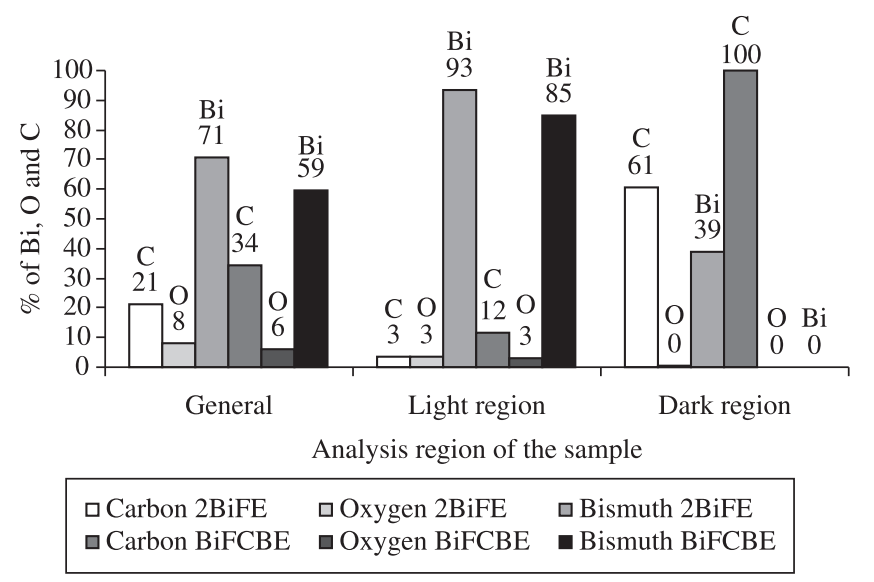

Figure 4. Percentage of carbon, oxygen and bismuth obtained by EDS in electrodes modified with bismuth films.

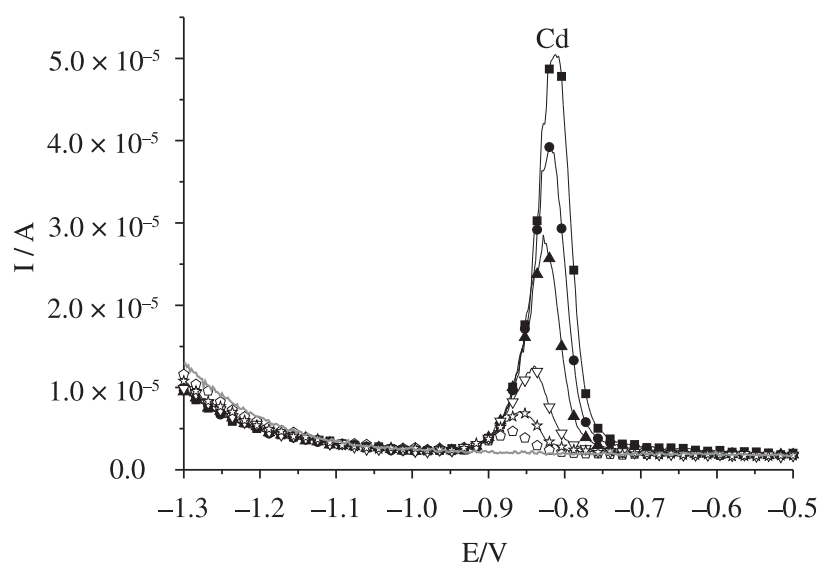

(a)

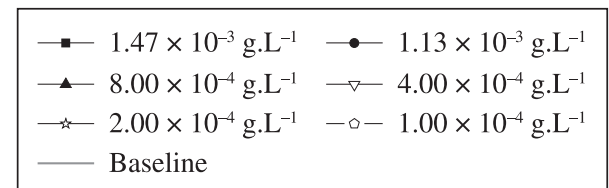

\subsection{Calibration data}

In evaluating the analytical performance of the electrodes in the quantitative determination of cadmium and zinc, it was necessary to characterize the electrodes with respect to calibration, repeatability and detection limits. Diluted aliquots of standard solutions of cadmium or zinc were added to the electrolyte with the aid of a variable-volume micropipette (100 to $1000 \mu \mathrm{L}$ ). Voltammograms of differential pulse anodic stripping were measured in the solution containing only the supporting electrolyte and after the addition of each aliquot, totaling six voltammograms, which were used to build the calibration curves.

These types of measurements have been repeated three times for every concentration and sample, and the resulting average and standard deviation values have been used to establish the calibration plots shown in Figure 6. Before each sequence of analysis, the surface of each electrode was sanded. The resulting data of the corresponding regression equations for all electrodes are given in Table 1.

The resulting calibration plots were used to estimate the detection limits. The LOD was calculated as the ratio of three times the blank standard deviation for the slope, according to Equation 1. Lower values of LOD can be obtained using longer deposition and/or a rotating electrode system.

$$
\begin{aligned}
& L O D=\frac{3 S d}{S} \\
& \text { - } \mathrm{Sd}-\text { standard deviation } \\
& \text { - } \mathrm{S}-\text { slope }
\end{aligned}
$$

\subsection{Electrode sensitivity}

The graphs of the analytical curves presented in Figure 6 and the data presented in Table 1 can be used to evaluate the linearity of the responses obtained with the electrodes used. It was observed that the linearity is greater when analysis is performed with the electrode without the bismuth film. In the determination of zinc with

\begin{tabular}{|c|c|}
\hline$-3.00 \times 10^{-3}$ g. $\mathrm{L}^{-1}$ & $\longrightarrow 2.66 \times 10^{-3}$ g. $\mathrm{L}^{-1}$ \\
\hline$\simeq 2.00 \times 10^{-3}$ g. $\mathrm{L}^{-1}$ & $\neg 1.33 \times 10^{-3} \mathrm{~g} . \mathrm{L}^{-1}$ \\
\hline $\begin{array}{l}\longrightarrow 6.66 \times 10^{-4} \text { g. } \mathrm{L}^{-1} \\
- \text { Baseline }\end{array}$ & $\prec 3.33 \times 10^{-4}$ g. $L^{-1}$ \\
\hline
\end{tabular}
the bismuth film, the peak currents did not show a linear variation

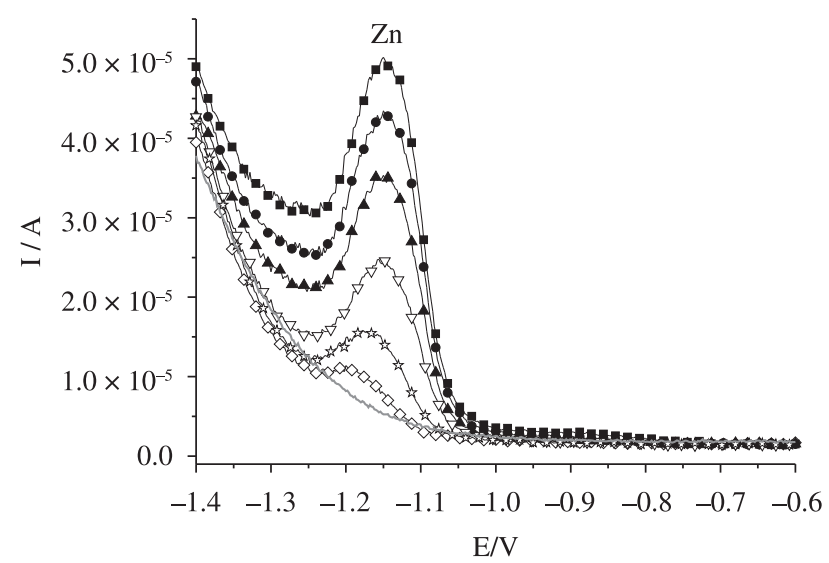

(b)

Figure 5. DPASV in $0.1 \mathrm{~mol} . \mathrm{L}^{-1}$ acetate buffer $\mathrm{pH}=4.5$ at $2 \mathrm{BiE}$ in the presence of different concentrations of a) $\mathrm{Cd}$; and b) $\mathrm{Zn}$. Conditions: scan rate $30.77 \mathrm{mV} / \mathrm{s}$, deposition time 60 seconds, pulse height of $90 \times 10^{-3} \mathrm{~V}$ and scan increment of $2.00 \mathrm{mV}$. 


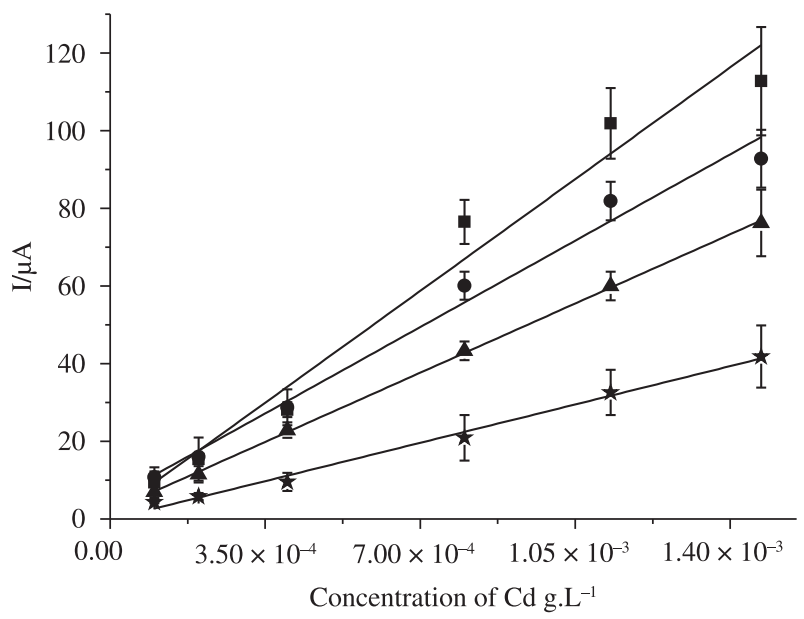

(a)

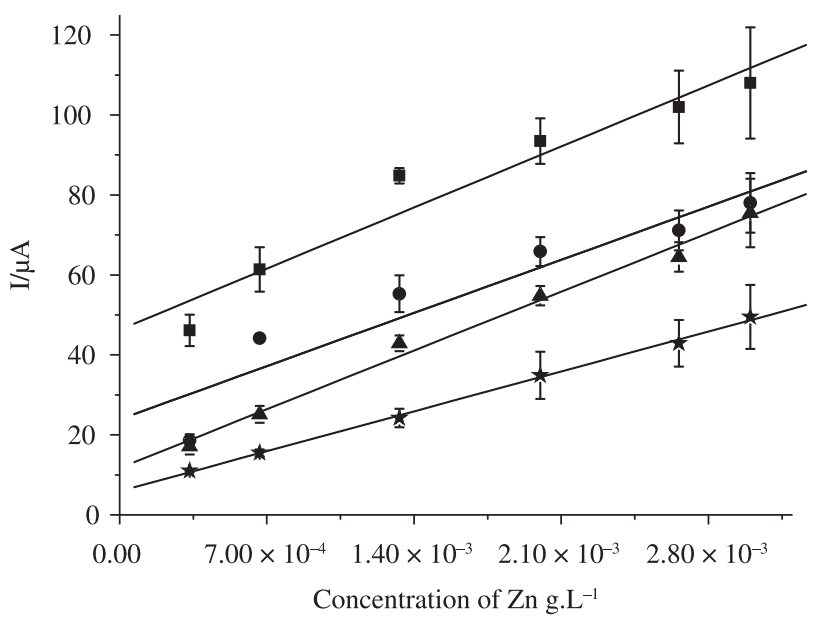

(b)

$\mathrm{BiFCBE} \bullet 2 \mathrm{BiFE} \Delta \mathrm{CBE} \star 2 \mathrm{BiE}$

Figure 6. Calibration curves for a) $\mathrm{Cd}$; and b) $\mathrm{Zn}$ in different concentrations for $\mathrm{CBE}$ and $2 \mathrm{BiE}$ electrodes with and without bismuth films. Standard deviations are given for $\mathrm{n}=3$.

Table 1. Limits of detection, sensitivity, intercept and correlation coefficients obtained in the analysis of cadmium and zinc electrodes CBE, 2BiE, BiFCBE and $2 \mathrm{BiFE}$.

\begin{tabular}{|c|c|c|c|c|c|}
\hline Electrode & Analyte & $\begin{array}{c}\text { Intercept } \\
\quad(\mu \mathrm{A})\end{array}$ & $\begin{array}{l}\text { Correlation } \\
\text { coefficient }\end{array}$ & $\begin{array}{l}\text { Sensitivity } \\
\left(\mu \mathrm{A} / \mu \mathrm{g} . \mathrm{L}^{-1}\right)\end{array}$ & $\begin{array}{l}\text { Limit of } \\
\text { detection } \\
\left(\text { g. } \mathrm{L}^{-1}\right)\end{array}$ \\
\hline $\mathrm{CBE}$ & $\mathrm{Cd}$ & 1.97 & 0.9992 & 0.0481 & $6.41 \times 10^{-5}$ \\
\hline $2 \mathrm{BiE}$ & $\mathrm{Cd}$ & 0.003 & 0.9980 & 0.0343 & $1.50 \times 10^{-4}$ \\
\hline BiFCBE & $\mathrm{Cd}$ & 1.77 & 0.9745 & 0.0876 & $3.07 \times 10^{-5}$ \\
\hline 2BiFE & $\mathrm{Cd}$ & 2.14 & 0.9874 & 0.0686 & $5.56 \times 10^{-5}$ \\
\hline $\mathrm{CBE}$ & $\mathrm{Zn}$ & 11.71 & 0.9904 & 0.0210 & $5.18 \times 10^{-4}$ \\
\hline $2 \mathrm{BiE}$ & $\mathrm{Zn}$ & 5.93 & 0.9980 & 0.0143 & $8.13 \times 10^{-4}$ \\
\hline BiFCBE & $\mathrm{Zn}$ & 46.32 & 0.9394 & 0.0218 & $1.53 \times 10^{-4}$ \\
\hline 2BiFE & $\mathrm{Zn}$ & 23.89 & 0.8867 & 0.0190 & $1.24 \times 10^{-4}$ \\
\hline
\end{tabular}

with concentration, and the reduction of hydrogen ions may have contributed to this result.

Cesarino et al. ${ }^{19}$ observed that bismuth deposition at Graphitecastor oil polyurethane composite electrodes at $-1.4 \mathrm{~V}$ occurs together with hydrogen evolution but that simultaneous heavy metal electrodeposition decreases hydrogen evolution.

The data presented by the electrodes modified with bismuth films in the determination of zinc were not satisfactory. The methods and the electrodes, under the conditions adopted in this work to determine zinc, were not reliable. This may be due to reduction of hydrogen on the surface of carbon electrodes because the surface was not fully covered by the bismuth film.

Sensitivity is the change in the response of a measuring instrument divided by the corresponding change in stimulus. In voltammetry analysis, the sensitivity is the signal output per unit concentration of a substance. The sensitivity of the responses obtained using electrodes with and without a bismuth film was measured by DPASV analysis with increasing concentrations of cadmium and zinc; the results are shown in Table 1.

Through the values presented in Table 1, we can see an improvement of electrode sensitivity in the presence of a bismuth film.
Furthermore, the BiFCBE electrode showed the best performance among the electrodes studied in relation to sensitivity for the analysis of cadmium and zinc, as confirmed by the values presented in Table 1 that were obtained with electrodes. However, the data obtained in the determination of zinc may not be accurate, as indicated by the low coefficient of correlation.

The results presented are in agreement with those obtained by Malakhova et al. ${ }^{22}$ who made a comparison between microscopic and electrochemical data and suggested that different surface microstructures of the electrodes have a considerable effect on their electrochemical properties.

\section{Conclusions}

We have shown by means of SEM and EDS that bismuth films do not entirely cover the surface of the electrodes. Thus, the responses varied because the surface characteristics strongly affect the sensitivity of electroanalytical electrodes.

In this work, we presented the results of sensitivity analysis for all electrodes with respect to the metals present in aqueous solution. The BiFCBE electrode was more sensitive for the determination of cadmium and zinc present in aqueous solution. The presence of a bismuth film on the surface of the electrodes provided the increase in the sensitivity in the detection of these elements. However, our data indicate that the method to assay zinc is not reliable with electrodes modified with bismuth film.

\section{Acknowledgements}

The authors would like to thank the CNPq for financial support, the Post-Graduation Program of Mechanic Engineering and Materials (PPGEM), and the Electronic Scanning Microscopy Center of the UFPR.

\section{References}

1. Hwang GH, Han WK, Park JS and Kang SG. Determination of trace metals by anodic stripping voltammetry using a bismuth-modified carbon nanotube electrode. Talanta. 2008; 76:301-308. PMid:18585281. http://dx.doi.org/10.1016/j.talanta.2008.02.039 
2. Wang J, Lu J, Hocevar SB and Farias PAM. Bismuth-Coated Carbon Electrodes for Anodic Stripping Voltammetry. Analytical Chemistry. 2000; 72:3218-3222. PMid:10939390. http://dx.doi.org/10.1021/ac000108x

3. Hutton EA, Elteren JT, Ogorevc B and Smyth MR. Validation of bismuth film electrode for determination of cobalt and cadmium in soil extracts using ICP-MS. Talanta. 2004; 63:849-855. PMid:18969509. http://dx.doi. org/10.1016/j.talanta.2003.12.038

4. Economou A and Voulgaropoulos A. On-line stripping voltammetry of trace metals at a flow-through bismuth-film electrode by means of a hybrid flow-injection/sequential-injection system. Talanta. 2007; 71:758-765. PMid:19071370. http://dx.doi.org/10.1016/j.talanta.2006.05.021

5. Economou A and Voulgaropoulos A. Stripping Voltammetry of Trace Metals at Bismuth-Film Electrodes by Batch-Injection Analysis. Electroanalysis. 2010; 22(13):1468-1475. http://dx.doi.org/10.1002/ elan.200970007

6. Economou A. Bismuth-film electrodes: recent developments and potentialities for electroanalysis. Trends in Analytical Chemistry. 2005; 24:334-340. http://dx.doi.org/10.1016/j.trac.2004.11.006

7. Serrano N, Díaz-Cruz JM, Ariño C and Esteban M. Stripping analysis of heavy metals in tap water using the bismuth film electrode. Analytical and Bioanalytical Chemistry. 2010; 396:1365-1369. http://dx.doi.org/10.1007/ s00216-009-3294-7

8. Królicka A, Pauliukaite R, Svancara I, Metelka R, Bobrowski A, Norkus E et al. Bismuth-film-plated carbon paste electrodes. Electrochemistry Communications. 2002; 4:193-196. http://dx.doi.org/10.1016/S13882481(01)00301-0

9. Hutton EA, Hocevar SB and Ogorevc B. Ex situ preparation of bismuth film microelectrode for use in electrochemical stripping microanalysis. Analytica Chimica Acta. 2005; 537:285-292. http://dx.doi.org/10.1016/j. aca.2005.01.040

10. Anastasiadou ZD, Jannakoudakis PD and Girousi ST. Square wave anodic stripping voltammetry determination of eco-toxic metals in samples of biological and environmental importance. Central European Journal of Chemistry. 2010; 8(5):999-1008. http://dx.doi.org/10.2478/ s11532-010-0091-2

11. Kefala G, Economou A and Voulgaropoulos A. A study of Nafion-coated bismuth-film electrodes for the determination of trace metals by anodic stripping voltammetry. Analyst. 2004; 129:1082-1090. http://dx.doi. org/10.1039/b404978k
12. Rehacek V, Hotovy I, Vojs M and Mika F. Bismuth film electrodes for heavy metals determination. Microsystem Technologies. 2008; 14:491-498. http://dx.doi.org/10.1007/s00542-007-0432-z

13. Flechsig GU, Kienbaum M and Grundler P. Ex situ atomic force microscopy of bismuth film deposition at carbon paste electrodes. Electrochemistry Communication. 2005; 7:1091-1097. http://dx.doi. org/10.1016/j.elecom.2005.08.003

14. Metelka R, Vytras K and Bobrowski A. Effect of the modification of mercuric oxide on the properties of mercury films at $\mathrm{HgO}$-modified carbon paste electrodes. Journal of Solid State Electrochemistry. 2000; 4:348-352. http://dx.doi.org/10.1007/s100080000133

15. Mendes RK, Cervini $P$ and Cavalheiro ETG. The use of a graphitecastor oil polyurethane composite electrode for the determination of hydroquinone in photographic developers. Talanta. 2006; 68:708-712. http://dx.doi.org/10.1016/j.talanta.2005.05.012

16. Mendes RK, Claro-Neto S and Cavalheiro ETG. Evaluation of a new rigid carbon-castor oil polyurethane composite as an electrode material Talanta. 2002; 57:909-917. http://dx.doi.org/10.1016/S00399140(02)00122-4

17. Cervini P. Aplicação de eletrodos compósitos a base de poliuretanagrafite. [Tese]. São Carlos: Universidade de São Paulo; 2006. 191 p.

18. Toledo RA and Vaz CMP. Use of a graphite-polyurethane composite electrode for electroanalytical determination of indole-3-acetic acid in soil samples. Microchemical Journal. 2007; 86:161-165. http://dx.doi. org/10.1016/j.microc.2007.02.002

19. Cesarino I, Gouveia-Caridade C, Pauliukaite R, Cavalheiro ETG and Bretta CMA. Characterization and Application of Bismuth-Film Modified Graphite-Polyurethane Composite Electrodes. Electroanalysis. 2010; 22(13):1437-1445. http://dx.doi.org/10.1002/elan.200970003

20. Bobrowski A, Nowak K and Zarebski J. Application of a bismuth film electrode to the voltammetric determination of trace iron using a Fe(III)TEA-BrO3- catalytic system. Analytical and bioanalytical chemistry. 2005; 382:1691-1697. http://dx.doi.org/10.1007/s00216-005-3313-2

21. Baldrianova L, Svancara I, Vlcek M, Economou A and Sotiropoulos S. Effect of Bi(III) concentration on the stripping voltammetric response of in situ bismuth-coated carbon paste and gold electrodes. Electrochimica Acta. 2006; 52:481-490. http://dx.doi.org/10.1016/j.electacta.2006.05.029

22. Malakhova NA, Stojko NY and Brainina KZ. Novel approach to bismuth modifying procedure for voltammetric thick film carbon containing electrodes. Electrochemistry Communications. 2007; 9:221-227. http://dx.doi.org/10.1016/j.elecom.2006.09.003 